\title{
Human papillomavirus load and physical status in sinonasal inverted papilloma and squamous cell carcinoma*
}

\author{
Masahiro Hasegawa, Zeyi Deng, Hiroyuki Maeda, Yukashi Yamashita, Sen \\ Matayoshi, Asanori Kiyuna, Shinya Agena, Takayuki Uehara, Mikio Suzuki \\ Rhinology 50: 87-94, 2012 \\ DOI: $10.4193 /$ Rhino.11.106 \\ Department of Otorhinolaryngology, Head and Neck Surgery, Graduate School of Medicine, \\ *Received for publication: \\ University of the Ryukyus, Okinawa, Japan \\ May 18, 2011 \\ accepted: October 9, 2011
}

\section{Summary \\ Background: This study investigated prospectively the role of human papillomavirus (HPV) in paranasal inverted papilloma (IP).}

Methods: HPV presence and viral load and physical status of HPV-16 were examined by polymerase chain reaction-based methods using fresh frozen samples obtained from 13 patients with IP (IP group), 11 with squamous cell carcinoma in the maxillary sinus (SCC group) and 39 with chronic inflammatory lesions (inflammatory group).

Results: The presence of the HPV genome was detected in $46.1 \%, 27.3 \%$ and $7.6 \%$ of patients in the IP, SCC and inflammatory groups, respectively. The IP group showed significantly higher HPV-positive rates than the inflammatory group. All types of HPV detected were high-risk HPV, especially HPV-16. The relative HPV-16 copy numbers varied from 2.5 to 1524.1 per $50 \mathrm{ng}$ genomic DNA. The viral load was higher in the IP and SCC groups than in the inflammatory group. In the IP group, no significant relationship was found between HPV-16 viral load and clinical characteristics, or between physical status and clinical characteristics. One patient with IP and concomitant squamous cell carcinoma, however, showed high viral load and integration.

Conclusions: HPV infection is involved in the pathogenesis of IP, and high viral load and integration of HPV have an important role in malignant lesion in association with IP.

Key words: inverted papilloma, integration, viral load, human papillomavirus, paranasal sinus

\section{Introduction}

Inverted papilloma (IP) of the paranasal sinus is a benign neoplasm with unique clinical characteristics, particularly a high recurrence rate and the association with malignant lesions. The recommended treatment for IP is complete surgical excision. Recently, endoscopic tumour resection has become the standard surgical approach for the management of IP. According to several meta-analyses of IP treatment, local recurrence of endoscopic resection and malignant lesion in association with IP is estimated to be approximately $11.8-15.0 \%$ and 8.0 $-9.3 \%$, respectively ${ }^{(1-3)}$. In certain cases, it is very difficult to diagnose and control tumour recurrence and/or concomitant malignant lesions due to anatomical alterations from previous operations, such as bony hypertrophy and substantial scarring. Therefore, effective diagnostic markers to predict local recurrence and malignant lesion are needed.

There have been several reports regarding the close relationship between IP and human papillomavirus (HPV) infection. Beck et al., not only found that $63 \%$ of IP cases were positive for HPV DNA, but also that the presence of HPV sequences predicted recurrence of $I P{ }^{(4,5)}$. They reported recurrence in 13 of 15 patients whose tumours were positive for HPV, whereas only one of 10 patients with HPV-negative tumours experienced 
recurrence ${ }^{(4)}$.

Moreover, they found that patients with HPV types 16 or 18 had a higher rate of associated malignancy than patients with HPV types 6 or $11^{(5)}$. However, other authors have not found a significant correlation between malignant lesions in IP and the HPV type ${ }^{(6,7)}$.

Many methods are available to detect HPV DNA in samples and include Southern blotting, in situ hybridisation (ISH) and polymerase chain reaction $(\mathrm{PCR})^{(4-7)}$. As IP is a relatively rare tumour, most previous studies have used formalin-fixed paraffinembedded archival tissue. PCR amplification is more efficient on frozen samples than on paraffin-embedded samples, as it is known that the fixation procedure leads to DNA fragments that are often shorter than $200 \mathrm{bp}{ }^{(8)}$. In the present study, to clarify the clinical importance of HPV in IP, viral load and physical status of HPV were prospectively examined using fresh frozen samples of IP, squamous cell carcinoma (SCC) of the maxillary sinus and sinonasal inflammatory mucosa.

\section{Subjects and methods}

Study design

A total of 13 patients with IP in the paranasal sinus (IP group; 5 males, 8 females; age range 46 - 76 years; median age 57 years) participated in this study. All patients underwent surgery (conducted by M.H. and M.S.) between 2008 and 2010. IP specimens obtained during surgery were stored in liquid nitrogen for further analysis.

For comparison, specimens from 11 patients with SCC in the maxillary sinus (SCC group) and inflammatory nasal or paranasal specimens from 39 patients with chronic sinusitis, maxillary cyst or allergic rhinitis (inflammatory group) were also collected and stored in liquid nitrogen for later analysis. The inflammatory group consisted of 34 patients with chronic sinusitis and 5 patients with post-operative mucoecele in the paranasal sinus. Specimens in the inflammatory group were sampled from nasal polyps and hypertrophic mucosa around cysts.

The study protocol was approved in advance by the Institutional Review Board of the University of the Ryukyus. All participants provided written informed consent according to the guidelines of the Ethics Committee of the University of the Ryukyus. This study was conducted in accordance with the principles of the Declaration of Helsinki.

\section{Patient characteristics}

The following data were noted in and later summarized from the clinical records of patients with IP: Krouse's stage ${ }^{(1)}$, tumour location, history of previous surgeries, surgical procedures undertaken, recurrence and malignant lesion.

Detection of HPV genome and identification of HPV types
Fresh frozen samples from the three groups were analysed to determine the prevalence of HPV and HPV types. A Gentra Purification Tissue kit (Qiagen, Germantown, MD, USA) was used to isolate DNA from the specimens according to the manufacturer's specifications. The presence and integrity of DNA was verified in all samples by PCR $\beta$-globin gene amplification using the primers $\mathrm{PCO} 4$ and $\mathrm{GH}_{2}{ }^{(9)}$. Negative controls using water and positive controls using DNA of HPV-16-positive CaSki cells were included in each amplification series.

The presence of HPV DNA was analysed by PCR using the general consensus primer sets GP5+/GP6+ and MY09/11 (10,11). DNA samples that were negative in the GP5+/GP6+ or MY9/11 PCR were re-amplified in a nested PCR using the GP5+/GP6+ primer pair as previously described ${ }^{(12)}$, which can increase the sensitivity of HPV detection.

PCR was performed in a programmable thermal cycler (VeritiTM 96-Well Thermal Cycler, Applied Biosystems, Carlsbad, CA, USA). Subsequently, $10 \mu \mathrm{L}$ reaction mixture was electrophoresed through $2 \%$ agarose gel containing $0.5 \mu \mathrm{g} / \mathrm{ml}$ ethidium bromide and visualised by ultraviolet transillumination.

After purification of positive PCR products, sequence analysis was performed on an ABI PRISM 3130xI Genetic Analyzer (Applied Biosystems). Obtained sequences were aligned and compared with those of known HPV types available from the GenBank database using the BLAST program.

\section{Viral load and physical status of HPV-16}

To investigate HPV-16 viral load and physical status, quantitative real-time PCR using HPV-16 DNA-positive samples was performed with the ABI Prism 7300 Sequence Detection System (Applied Biosystems) and TaqMan PCR Master Mix II (Roche Molecular Systems, Foster City, CA, USA). Primers and TaqMan probes that target the HPV-16 E6 and E2 open reading frames were used, as previously described ${ }^{(13)}$. Both E6 and E2 probes were labelled with FAM at the $5^{\prime}$ end and with TAMRA at the $3^{\prime}$ end (Applied Biosystems Japan Ltd, Tokyo, Japan). E2 primers and probe recognise the $\mathrm{E} 2$ hinge region, which was deleted on HPV-16 integration. Amplification conditions were $2 \mathrm{~min}$ at $50^{\circ} \mathrm{C}, 10 \mathrm{~min}$ at $95^{\circ} \mathrm{C}$ and a two-step cycle of $95^{\circ} \mathrm{C}$ for $15 \mathrm{~s}$ and $60^{\circ} \mathrm{C}$ for $60 \mathrm{~s}$, for a total of 50 cycles ${ }^{(13)}$. Two standard curves for the $\mathrm{E} 6$ and $\mathrm{E} 2$ genes were generated by amplification of serial 10 -fold dilutions $\left(10^{1}, 10^{2}, 10^{3}, 10^{4}, 10^{5}\right.$ and $10^{6}$ viral copies) of a plasmid $\mathrm{p} \beta$-actin carrying the complete HPV-16 early region (Addgene, Inc., Cambridge, MA, USA). For specificity and validity testing, DNA samples from the SiHa and the CaSki cell lines were examined. For cellular DNA quantification, an external standard curve was generated using known serial dilutions (0.3, 3,30 and $300 \mathrm{ng}$ ) of human genomic placental DNA (SigmaAldrich, St. Louis, MO, USA) ${ }^{(14)}$, and $\beta$-globin was amplified as described by van Duin et al., ${ }^{(15)}$. The amount of DNA (ng) was calculated by plotting the $\mathrm{Ct}$ (threshold cycle) values against the logarithm of the standard curve. The relative viral load was 
identified by calculating copies of specimen E6 in $50 \mathrm{ng}$ cellular DNA.

The physical status of HPV-16 was determined according to a previously described method ${ }^{(13)}$. The integrated E6 was calculated by subtracting the copy numbers of E2 (episomal) from the total copy numbers of E6 (episomal and integrated). Ratios of E2 copy number/total E6 of $<1$ indicate the presence of both integrated and episomal forms. The ratio of E2 to integrated E6 represents the amount of the episomal form in relation to the integrated form. An E2/E6 ratio nearly equal to 1 indicates predominance of the episomal form, whereas a ratio of 0 indicates the presence of only the integrated form ${ }^{(13)}$.

\section{Results}

Patient characteristics

According to Krouse's classification, T2, T3 and T4 stage tumours were observed in 2, 9 and 2 patients, respectively. Patients with T4 tumours included one with IP with massive extension to the pterygoid fossa and another with IP and concomitant SCC. Figure 1 shows the histological findings in the latter case with IP and SCC. Although the majority of the tissue specimen had the characteristics of IP, the invasive SCC was present, in part, in IP. The observation period following surgery ranged from 5 to 41 months, with a median of 17 months. At the first clinic visit, 7 patients had a previous history of sinus surgery. Tumour locations were widely distributed within the nasal and paranasal sinus, and 10 of 13 patients with IP had lesions in the maxillary sinus. The main surgical procedure carried out at our facility to treat IP was endoscopic resection, that is, standard endoscopic sinus surgery or transnasal endoscopic medial maxillectomy (Table 1). Local recurrence after surgery was observed in 2 patients (15.4\%), both of whom had a previous history of multiple sinus surgeries, with accompanying marked fibrosis and proliferation of osseous tissue in the nasal and paranasal cavity. Recurrent lesions were successfully salvaged through external approaches, such as external frontoethmoidectomy and lateral rhinotomy. Malignant lesion during the follow-up period was not observed in any patients with IP.

\section{HPV detection}

Figure 2 shows representative examples of the PCR results. Of 13 patients with IP, the HPV genome was detected in 6 patients (46.2\%, Table 2). By contrast, 3 of 11 (27.3\%) patients with maxillary SCC and 3 of 39 (7.7\%) patients with inflammatory diseases were positive for HPV. Patients in the IP group showed significantly higher HPV-positive rates than those in the inflammatory group ( $p<0.01$, chi-square).

Of $6 \mathrm{HPV}$-positive IP patients, the types of HPV included HPV-16 $(n=4)$ and HPV-33 $(n=2)$. All HPV-positive specimens obtained from patients in the SCC and inflammatory groups contained the HPV-16 genome. Multiple infections were not detected in the IP, SCC or inflammatory groups. In the IP group, there was no obvious relationship between HPV presence and clinical features of IP (Table 3, chi-square).

\section{Localisation of HPV genome}

Samples from 3 of the $6 \mathrm{HPV}$-positive IP patients in whom the inferior turbinates adjacent to the IP were not affected by IP, were subjected to PCR to determine the presence of HPV. As a control, samples from 4 of $7 \mathrm{HPV}$-negative IP patients with inferior turbinates adjacent to the IP were also examined. No positive PCR reactions were observed in HPV-positive or -negative IP patients.

\section{Viral load and physical status of HPV-16}

As the most common HPV type detected was HPV-16, viral load and physical status of HPV-16 were investigated in the IP, SCC and inflammatory groups. Both validated assays of the realtime PCR for E2 and E6 genes using serially diluted HPV-16 early region plasmid DNA showed similar amplification efficiencies, as reflected by the almost identical slopes of the amplification curves.

Viral load and physical status of HPV-16 in IP, paranasal carcinoma and inflammatory diseases are shown in Table 4. E6 copy number per 50 ng genomic DNA in HPV-16-positive specimens varied from 2.5 to 1524.1. Although statistical analysis cannot be carried out because of the small number of cases, the IP and SCC groups showed relatively high viral load, compared with the inflammatory group. According to physical status, all specimens in the SCC group showed mixed type integration of HPV-16. By contrast, the IP group had 1 case of mixed type with concomitant SCC and IP and 3 cases of episomal types, and the inflammatory group had 1 case of mixed type and 2 of episomal types. There were no significant relationships in the IP group between HPV-16 viral load and clinical characteristics, for example, tumour staging and recurrence, or between physical status and clinical characteristics. However, the patient with IP and concomitant SCC showed a high E6 copy number and mixed type integration.

\section{Discussion}

To our knowledge, this is the first prospective study to simultaneously evaluate HPV presence, HPV viral load and physical status in IP, cancerous lesions and inflammatory lesions using fresh frozen samples. The results of previous studies to determine HPV presence in IP have been inconsistent ${ }^{(16,17)}$. In the present study, HPV was detected in $46.1 \%$ of patients with IP, $27.3 \%$ with maxillary SCC and $7.6 \%$ with inflammatory diseases. Although the reason for the differences in HPV presence among studies remains unclear, sample preparation (i.e. fresh frozen or paraffin embedded), methods for HPV detection (i.e. PCR, Southern blotting or ISH) and geographic factors may be the 


\begin{tabular}{|c|c|c|c|c|c|c|c|c|c|c|c|c|c|}
\hline ड़ & คั & gั & 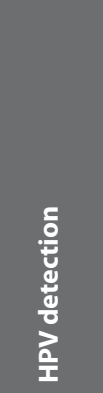 & 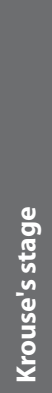 & 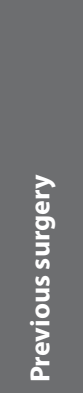 & 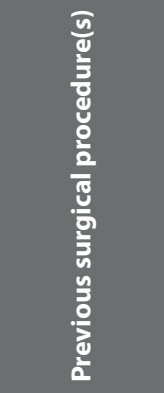 & 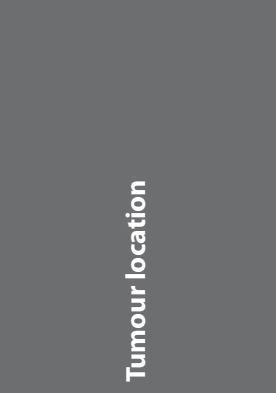 & 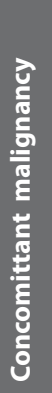 & 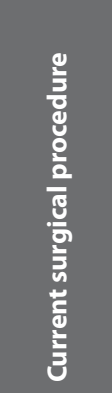 & 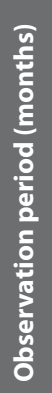 & 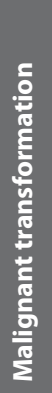 & 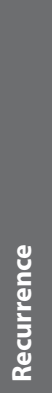 & $\begin{array}{l}\frac{5}{0} \\
\frac{0}{0} \\
\frac{0}{0} \\
\frac{0}{0} \\
\frac{0}{0}\end{array}$ \\
\hline 1 & $\mathrm{~F}$ & 49 & none & $\mathrm{T} 2$ & none & none & MW & - & ESS & 9 & - & - & \\
\hline 2 & M & 46 & HPV16 & T3 & 2 & ESS ( 2 times) & Et, FS, MW & - & ESS & 41 & - & + & $\begin{array}{l}\text { External frontoeth- } \\
\text { moidectomy } \\
\text { (34 months) }\end{array}$ \\
\hline 3 & $M$ & 54 & HPV16 & T3 & 1 & ESS & SS, SupT & - & ESS & 18 & - & - & \\
\hline 4 & $\mathrm{~F}$ & 52 & none & T3 & none & none & MW, IW & - & ESS, Luc & 15 & - & - & \\
\hline 5 & $\mathrm{~F}$ & 63 & HPV33 & T3 & 1 & ESS & MW, IW & - & TEMM & 17 & - & - & \\
\hline 6 & $\mathrm{~F}$ & 60 & none & T3 & none & none & MW, IW, Et & - & TEMM & 31 & - & - & \\
\hline 7 & $\mathrm{~F}$ & 48 & none & T3 & none & none & MW, IW, PW, AW, Et & - & TEMM & 24 & - & - & \\
\hline 8 & $M$ & 62 & HPV16 & $\mathrm{T} 2$ & none & none & MW, Et, SupT, MidT & - & ESS & 19 & - & - & \\
\hline 9 & M & 75 & none & $\mathrm{T} 4$ & 2 & $\begin{array}{l}\text { Luc, lateral } \\
\text { rhinotomy }\end{array}$ & MW, SW, PW, Et, Ptery & - & Luc & 18 & - & + & $\begin{array}{l}\text { Lateral rhinotomy } \\
\qquad(13 \text { months })\end{array}$ \\
\hline 10 & $\mathrm{~F}$ & 58 & HPV16 & $\mathrm{T} 4$ & none & none & MW, IW, SW, AW, LW & + & $\begin{array}{l}\text { TEMM, } \\
\text { LuC }\end{array}$ & 7 & - & - & \\
\hline 11 & $\mathrm{~F}$ & 49 & none & T3 & 1 & ESS & MW, IW, SW & - & TEMM & 6 & - & - & \\
\hline 12 & M & 58 & none & T3 & 1 & ESS & SS, SupT & - & ESS & 6 & - & - & \\
\hline 13 & M & 76 & HPV33 & T3 & 1 & ESS & Et, SS & - & TEMM & 10 & - & - & \\
\hline
\end{tabular}

ESS: endoscopic sinus surgery; TEMM: transnasal endoscopic medial maxillectomy; Luc: Luc's operation; MW: medial wall of maxillary sinus; IW: inferior wall of maxillary sinus; PW: posterior wall of maxillary sinus; AW: anterior wall of maxilary sinus; LW: lateral wall of maxillary sinus; Et: ethmoid sinus; SS: sphenoid sinus; FS: frontal sinus; SupT: superior turbinate; MidT; middle turbinate; Ptery: pterygoid fossa

source of the contradictory results. Despite a few studies that used fresh frozen samples of IP (18), the majority of previous studies to investigate HPV presence in IP employed formalin-fixed paraffin-embedded archival tissues ${ }^{(16,17)}$. Specimen storage with or without fixation, and the duration of tissue storage are important factors for HPV detection because of their influence on DNA preservation and retrieval efficiency for $\mathrm{PCR}{ }^{(8,19)}$. DNA extraction from frozen samples generally leads to better DNA extraction and thus greater sensitivity for molecular analysis. Therefore, fresh frozen samples were used for prospective HPV analysis in the present study. The use of varying methods for $\mathrm{HPV}$ detection is also a possible cause of the wide range of observed HPV rates. PCR is a suitable and economical assay that is comparable to ISH with regard to sensitivity, and may provide logistical advantages compared to ISH for assessing HPV status in oropharyngeal malignancies ${ }^{(20)}$. Indeed, a significantly higher rate of HPV positivity was detected among cervical cancer samples with PCR than with catalysed signal amplification ISH (21). Geographic factors may also be important. Lawson et al., reported that HPV presence was not different among patients from North America, Europe and East Asia ${ }^{(17)}$. However, analysis of HPV infection in head and neck squamous cell carcinoma showed a geographic difference of HPV viral load and rate of HPV presence across East Asia ${ }^{(22)}$. More precise analysis of geographic factors that regulate specimen storage and detection methods is needed to clarify these geographic differences. 
Table 2. Detection of human papillomavirus (HPV).

\begin{tabular}{|c|c|c|c|}
\hline & \multicolumn{3}{|c|}{$\begin{array}{c}\text { Human } \\
\text { papillomavirus }\end{array}$} \\
\hline & Positive & Negative & $\begin{array}{c}\text { Positive rate } \\
(\%)\end{array}$ \\
\hline IP group & 6 & 7 & 46,2 \\
\hline$n=13$ & $\begin{array}{l}\text { HPV16: } 4 \\
\text { HPV33: } 2\end{array}$ & & \\
\hline SCC group & 3 & 8 & 27,3 \\
\hline $\mathrm{n}=11$ & HPV16: 3 & & \\
\hline Inflammatory gorup & 3 & 36 & 7,7 \\
\hline $\mathrm{n}=39$ & HPV16: 3 & & \\
\hline
\end{tabular}

Table 3. Relationship between HPV presence and clinical characteristics.

$\begin{array}{ccc}\text { HPV(+) } & \text { HPV(-) } & \text { Total } \\ \text { (n) } & \text { (n) } & \text { (n) }\end{array}$

$\begin{array}{llll}\text { Sex } & 4 & 2 & 6 \\ \text { Male } & 2 & 5 & 7 \\ \text { Female } & & & \\ \text { Age } & 3 & 5 & 8 \\ <60 & 3 & 2 & 5 \\ \geq 60 & 1 & 1 & \\ \text { Krouse's stage } & 4 & 2 \\ \text { T2 } & 1 & 5 & 9 \\ \text { T3 } & & 1 & 2 \\ \text { T4 } & & & 6 \\ \text { Previous surgery } & 2 & 4 & 7 \\ \text { No } & 4 & 3 & 6 \\ \text { Yes } & & & \end{array}$

Table 4. Physical status of HPV16 in specimens.

\begin{tabular}{|c|c|c|c|c|}
\hline Specimen & HPV type & $\begin{array}{c}\text { E6 (copies/50 ng } \\
\text { genomic DNA) }\end{array}$ & E2/E6 & Physical status \\
\hline \multicolumn{5}{|l|}{ IP group } \\
\hline IP (case 2) & 16 & 74 & 1 & Episomal \\
\hline IP (case 3) & 16 & 24.2 & 1 & Episomal \\
\hline IP (case 8) & 16 & 2.5 & 1 & Episomal \\
\hline IP + SCC (case 10) & 16 & 1524.1 & 0.65 & Mixed \\
\hline IP (case 5) & 33 & & & \\
\hline IP (case 13) & 33 & & & \\
\hline \multicolumn{5}{|l|}{ SCC group } \\
\hline Maxillary SCC & 16 & 594 & 0.46 & Mixed \\
\hline Maxillary SCC & 16 & 79 & 0.09 & Mixed \\
\hline Maxillary SCC & 16 & 35 & 0.11 & Mixed \\
\hline \multicolumn{5}{|l|}{$\begin{array}{l}\text { Inflammatory } \\
\text { group }\end{array}$} \\
\hline Sinusitis & 16 & 11.6 & 1 & Episomal \\
\hline Sinusitis & 16 & 5.1 & 0.12 & Mixed \\
\hline Sinusitis & 16 & 6.8 & 1 & Episomal \\
\hline
\end{tabular}



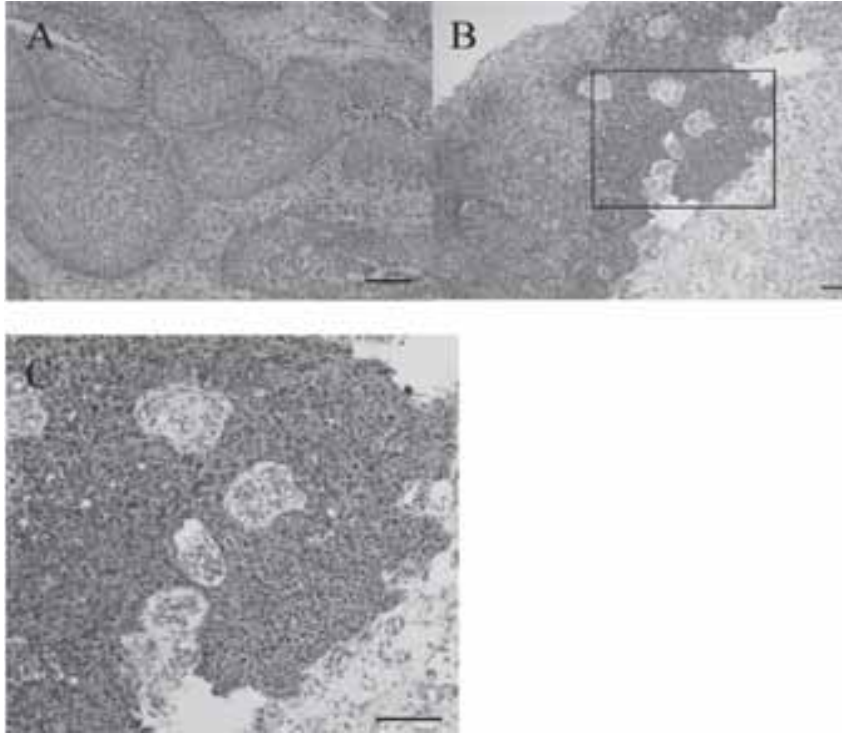

Figure 1. Histological findings of inverted papilloma with squamous cell carcinoma.

(A): The majority of samples obtained during sinus surgery showed inversion of the multilayer epithelium into the underlying oedematous stroma. Scale bar $=200 \mu \mathrm{m}$.

(B) Dysplastic squamous epithelium was transformed into invasive carcinoma with destruction of the basement membrane. Scale bar $=100 \mu \mathrm{m}$. (C) Enlargement of the rectangular portion in (B). The tumour cells show marked atypia, an increased nuclear to cytoplasmic ratio, conspicuous nucleoli and a loss of polarity; these cells were diagnosed as non-keratinising squamous cell carcinoma. Scale bar $=100 \mu \mathrm{m}$.

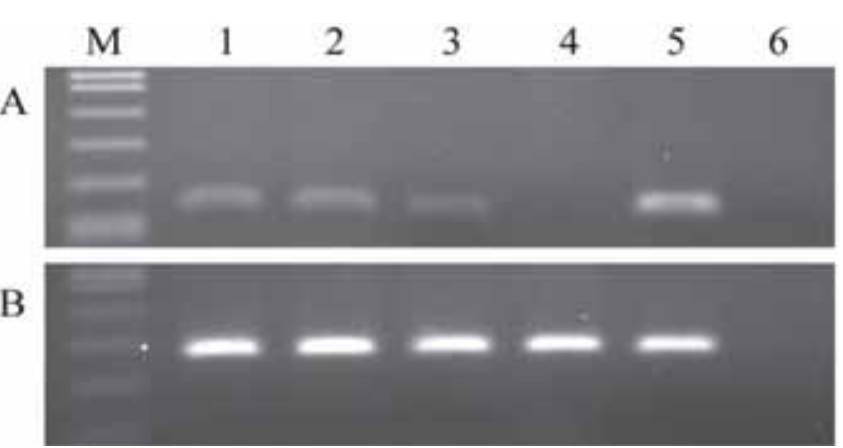

Figure 2. Representative examples of PCR electrophoresis using consensus primer set GP5+/GP6+.

(A): The 150-bp bands were observed as amplicons of HPV DNA.

(B): The 268-bp bands were observed as amplicons of beta-globin DNA to ensure the quality of the DNA.

M: DNA marker; lane 1: HPV-16-positive maxillary SCC; lane 2: HPV-16positive inverted papilloma with SCC; lane 3: HPV-16-positive inverted papilloma without SCC; lane 4: nasal sinusitis; lane 5: PC: positive control (SiHa cell); lane 6: NC: negative control (no template DNA).
In the present study, the presence of HPV was limited to the tumour itself and did not spread to neighbouring areas. Hoffmann et al., reported that tissue derived from normal mucosa adjacent to the head and neck carcinoma showed no PCR amplification for HPV DNA ${ }^{(23)}$. Although the natural history of HPV has not been fully determined, generally this infection does not lead to visible lesions and may be cleared by the immune system within a short period of time ${ }^{(24)}$. The localisation of HPV in IP may reflect such a process.

The role of HPV in IP has not been well established. Several high- and low-risk HPV types have been reported in IP. In a study conducted in Japan, Katori et al., demonstrated the presence of low-risk HPV types (6 or 11) in 11 of 26 (42.3\%) IP patients and high-risk HPV (16 or 18 ) in 8 of $26(30.8 \%)$ patients ${ }^{(25)}$. In a US study, Beck et al., showed that 12 of 39 (31\%) patients were low-risk HPV positive and 8 of 39 (21\%) were high-risk HPV positive ${ }^{(5)}$. By contrast, Hoffmann et al., (18) and Kraft et al., ${ }^{(7)}$ detected only low-risk HPV-6 and 11 in IP (11.5\% and 3.0\%, respectively). In general, low-risk HPV-6 and 11 exist in episomal forms independent of squamous intraepithelial lesion grade in the cervix ${ }^{(26)}$. In the head and neck region, low-risk HPV is frequently observed in benign lesions such as laryngeal papilloma and exophytic nasal papilloma. The overall detection rate of HPV in IP varies among studies, ranging from $0 \%$ to $72.4 \%{ }^{(17)}$. Precise analysis of published reports demonstrated that HPV-6 and 11 were found in $17.8 \%$ of IP cases, whereas HPV-16 and 18 were present in $8.1 \%{ }^{(17)}$. In the present study, $46.1 \%$ of IP contained a high-risk HPV genome and the prevalence of HPV in IP was significantly higher than in the inflammatory group. There have been a few studies of HPV prevalence in inflammatory disease. Hoffmann et al., reported that 1 of 39 (2.6\%) patients had HPV-positive disease ${ }^{(27)}$, and Zaravinos et al., showed that 3 of 23 (13.0\%) patients were HPV positive ${ }^{(28)}$. Unfortunately, these studies did not provide information about HPV type. In the present study, we describe the HPV type in inflammatory nasal diseases. We found that the HPV prevalence (6.8\%) in inflammatory diseases fell between the previously reported values, and surprisingly the type of HPV was high-risk HPV-16, as in IP and SCC. We previously reported an HPV prevalence of $2.1 \%$ and the presence of HPV-33 in chronic tonsillitis ${ }^{(22)}$. From these data, it appears that there is a low incidence of HPV, even the high-risk type, in the upper respiratory tract. Marked differences in the prevalence of HPV between IP and inflammatory nasal diseases suggest that HPV infection is involved in the tumorigenesis of IP.

Although no correlation was found between malignant lesion in association with IP and HPV presence in some studies ${ }^{(6,7)}$, McKay et al., reported that HPV transcripts were present in 
IP with SCC positive for HPV, using real-time PCR ${ }^{(29)}$. In the present study, the mixed or integrated form of HPV was found in 1 of $4(25 \%)$ patients with IP and 1 of 3 with (33\%) inflammatory diseases, compared with all 3 patients with maxillary SCC. No significant relationship between clinical features of IP and HPV integration was observed in patients with IP because of the small number of subjects. However, it is interesting that a patient with IP with integrated HPV-16 also presented with concomitant SCC. In the inflammatory disease group, despite carrying the high-risk HPV, the viral load of high-risk HPV was low. Given that the patient with IP with integrated HPV and concomitant maxillary SCC had high-risk HPV and a relatively high viral load, malignant lesion observed in IP may be related to a high viral load in addition to high-risk HPV integration to the host genome. Further prospective studies with large samples are needed to clarify the role of HPV in the tumorigenesis and malignant lesion in association with IP.

\section{Acknowledgements}

This study was supported by KAKENHI 22791614 (a Grant-in-Aid for Young Scientists (B) from the Japan Society for the Promotion of Science) awarded to Dr. Hasegawa, and a grant from the Japan-China Medical Association to Dr. Deng.

\section{Authorship contributions}

$\mathrm{MH}$ obtained research grants for this study, acquired samples and clinical data, supervised the experiments and prepared the manuscript; DZ obtained research grants for this study, conducted the experimental studies and acquired data; $H M, Y Y, S M, A K$, SA and TU acquired samples and clinical data and performed data analysis; and MZ contributed to the study design, supervision of the experiments and manuscript review.

\section{Conflicts of interest statement}

There are no potential conflicts of interest relevant to this article to disclose.

\section{References}

1. Krouse $\mathrm{JH}$. Endoscopic treatment of inverted papilloma: safety and efficacy. Am J Otolaryngol. 2001: 22: 87-99.

2. Busquets JM, Hwang PH. Endoscopic resection of sinonasal inverted papilloma: a metaanalysis. Otolaryngol Head Neck Surg. 2006; 134: 476-482.

3. Batsakis JG, Suarez P. Schneiderian papillomas and carcinomas: a review. Adv Anat Pathol. 2001: 8: 53-64.

4. Beck JC, McClatchey KD, Lesperance MM, Esclamado RM, Carey TE, Bradford CR. Presence of human papillomavirus predicts recurrence of inverted papilloma. Otolaryngol Head Neck Surg. 1995; 113: 49-55.

5. Beck JC, McClatchey KD, Lesperance MM, Esclamado RM, Carey TE, Bradford CR. Human papillomavirus types important in progression of inverted papilloma. Otolaryngol Head Neck Surg. 1995; 113: 558-563.

6. Buchwald C, Franzmann MB, Jacobsen GK, Lindeberg $\mathrm{H}$. Human papillomavirus (HPV) in sinonasal papillomas: a study of 78 cases using in situ hybridization and polymerase chain reaction. Laryngoscope. 1995; 105: 66-71.

7. Kraft $M$, Simmen $D$, Casas $R$, Pfaltz $M$. Significance of human papillomavirus in sinonasal papillomas. J Laryngol Otol. 2001; 115: 709-714.

8. Karisen F, Kalantari M, Chitemerere M Johansson B, Hagmar B. Modifications of human and viral deoxyribonucleic acid by formaldehyde fixation. Lab Invest. 1994; 71 : 604-611.

9. Saiki RK, Scharf S, Faloona F, et al. Enzymatic amplification of beta-globin genomic sequences and restriction site analysis for diagnosis of sickle cell anemia. Science.
1985: 230: 1350-1354

0. De Roda Husman AM, Walboomers JM, van den Brule AJ, Meijer CJ, Snijders PJ. The use of general primers GP5 and GP6 elongated at their $3^{\prime}$ ends with adjacent highly conserved sequences improves human papillomavirus detection by PCR. J Gen Virol. 1995; 76: 1057-1062.

11. Manos MM, Ting Y, Wright DK, Lewis AJ, Broker TR, Wolinsky SM. Use of polymerase chain reaction amplification for the detection of genital human papillomaviruses. Cancer cells. 1989; 7: 209-214.

12. Remmerbach TW, Brinckmann UG, Hemprich A, Chekol M, Kuhndel K, Liebert UG. PCR detection of human papillomavirus of the mucosa: comparison between MY09/11 and GP5+/6+ primer sets. J Clin Virol. 2004; 30: 302-308

13. Peitsaro $P$, Johansson $B$, Syrjanen $S$. Integrated human papillomavirus type 16 is frequently found in cervical cancer precursors as demonstrated by a novel quantitative real-time PCR technique. J Clin Microbiol. 2002; 40: 886-891.

14. Wang-Johanning F, Lu DW, Wang Y, Johnson MR, Johanning GL. Quantitation of human papillomavirus 16 E6 and E7 DNA and RNA in residual material from ThinPrep Papanicolaou tests using real-time polymerase chain reaction analysis. Cancer. 2002; 94: 2199-2210

15. van Duin M, Snijders PJ, Schrijnemakers HF, et al. Human papillomavirus 16 load in normal and abnormal cervical scrapes: an indicator of CIN II/III and viral clearance. Int J Cancer. 2002: 98: 590-595.

16. Syrjanen KJ. HPV infections in benign and malignant sinonasal lesions. J Clin Pathol. 2003; 56: 174-181.

17. Lawson W, Schlecht NF, Brandwein-Gensler $M$. The role of the human papillomavirus in the pathogenesis of Schneiderian Inverted papillomas: an analytic overview of the evidence. Head Neck Pathol. 2008; 2: 49-59.

18. Hoffmann M, Klose N, Gottschlich S, et al. Detection of human papillomavirus DNA in benign and malignant sinonasal neoplasm. Cancer Lett. 2006; 239: 64-70.

19. Specht K, Richter T, Müller U, Walch A, Werner M, Höfler H. Quantitative gene expression analysis in microdissected archival formalinfixed and paraffin-embedded tumor tissue. Am J Pathol. 2001; 158: 419-429.

20. Agoston ES, Robinson SJ, Mehra KK, et al. Polymerase chain reaction detection of HPV in squamous carcinoma of the oropharynx. Am J Clin Pathol. 2010; 134: 36-41.

21. Dabić MM, Hlupić L, Babić D, Jukić $S$, Seiwerth S. Comparison of polymerase chain reaction and catalyzed signal amplification in situ hybridization methods for human papillomavirus detection in parafifin-embedded cervical preneoplastic and neoplastic lesions. Arch Med Res. 2004; 35: 511-516.

22. Deng Z, Hasegawa M, Matayoshi S, et al. Prevalence and clinical features of human papillomavirus in head and neck squamous cell carcinoma in Okinawa, southern Japan. Eur Arch Otorhinolaryngol. 2011; 268: 1625-1631.

23. Hoffmann M, Kahn T, Mahnke CG, Goeroegh T, Lippert BM, Werner JA. Prevalence of human papillomavirus in squamous cell carcinoma of the head and neck determined by polymerase chain reaction and southern blot hybridization: proposal for optimized diagnostic requirements. Acta Otolaryngol. 1998: 118: 138-144.

24. Zur Hausen H. Papillomavirus infections - a major cause of human cancers. BBA. 1996: 1288: F55-F78.

25. Katori H, Nozawa A, Tsukuda M. Markers of malignant transformation of sinonasal 
inverted papilloma. EJSO. 2005; 31: 905-911.

26. Hudelist G, Manavi M, Pischinger KID, et al. Physical state and expression of HPV DNA in benign and dysplastic cervical tissue: different levels of viral integration are correlated with lesion grade. Gynecol Oncol. 2004; 92: 873-880.

27. Hoffmann M, Kahn T, Goeroegh T, et al. Tracing human papillomavirus DNA in nasal polyps by polymerase chain reaction. Acta Otolaryngol. 2000; 120: 872-875.

28. Zaravinos A, Bizakis J, Spandidos A. Prevalence of human papilloma virus and human herpes virus type 1-7 in human nasal polyposis. J Med Virol. 2009; 81: 1613-1619.

29. McKay S, Gregoire L, Lonardo F, Reidy P, Mathong R, Lancaster WD. Human papillomavirus (HPV) transcripts in malignant inverted papilloma are from integrated HPV DNA. Laryngoscope. 2005; 115: 1428-1431.
Mikio Suzuk

Department of Otorhinolaryngology Head and Neck Surgery, Graduate School of Medicine University of the Ryukyus 207 Uehara, Nishihara-cho Okinawa 903-0215 Japan

Tel: +81-98-895-1183

Fax: +81-98-895-1428

E-mail: suzuki@med.u-ryukyu.ac.jp

\section{ADVERTISEMENT}

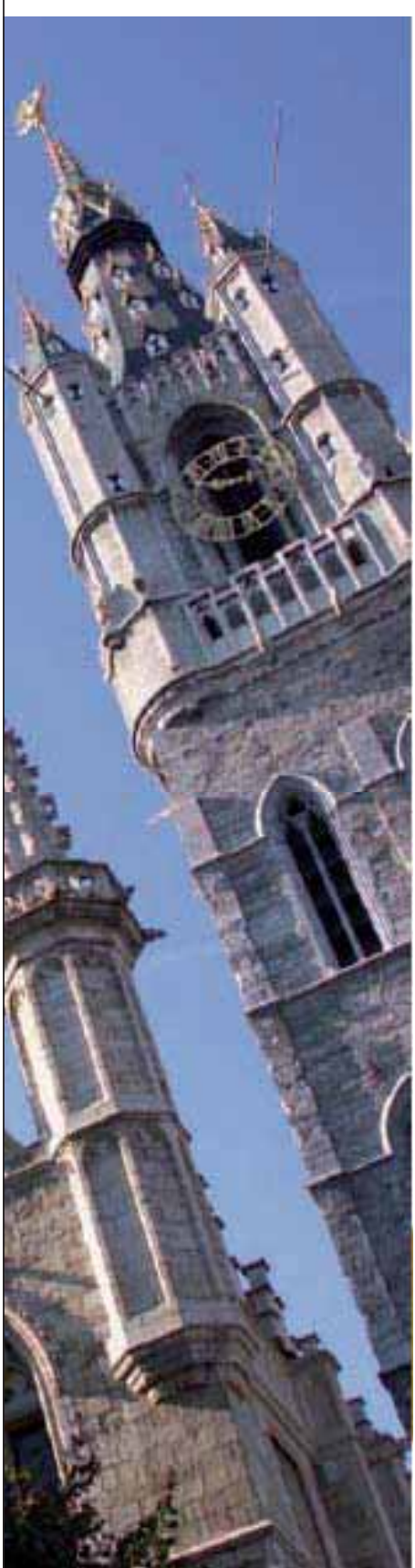

24th Intemational Course on

ENDOSCOPIC SURG ERY OF THE PARANASALSINUSES

$\&$

\section{SKULBASE \\ Ghent (Belgium) 22-25 August 2012}

A four-day course in a historic al city in Belgium

\section{www.FESS-C OURSE.be}

\section{EXIENDED INIERNATIONALFACULTY}

Bachert C (Ghent), Bemal Sprekelsen M (Barcelona), Close L (New York), Gevaert P (G hent), Hellings P (Leuven), Hosemann W (G reifswald),

SchaeferS (New York), Znreich J (Ba ltimore) SPECIAL GUESTS

Stammberger H (Graz)

\section{THE COURSE FATURES}

11h fully equipped cadaver dissection Lectures and round tables on endoscopic sinus surgery and its extensions (DCR, skull base, tumours etc), video sessions, cadaver head demonstration of current techniques, two hands-on cadaver dissections, surgery with navigation, post-operative care, up-date on sinusitis pathophysiology and skull base surgery, interactive discussion with the faculty members. Basic and advanced techniques will be demonstrated. Participants can actively perform surgery on 2 cadaver heads, with full video and mic rodebrider equipment.

REG ISTRATION FE BEFORE J UNE 1ST 2012

ENTspecialist $\quad 1600 €$

ENT resident in training* $\quad 1200 €$

Lectures and Live Surgery only $\quad 700 €$

Accompanying person $\quad 150 €$

*reduced registration fee after receipt certific ate

Registration fees may increase after $1^{\text {st }}$ of J une 2012

\section{INFORMATION}

Prof. C. Bachert C/o Mrs. Lieve Ectors Korte Meer 16, B- 9000 Ghent

E-mail: Fess@semico.be

orfax $+32(0) 92338597$

Under ERS Auspices 